Asian Review of Social Sciences

ISSN: 2249-6319 Vol.8 No.2, 2019, pp. 139-144

(C) The Research Publication, www.trp.org.in

\title{
The Saliva Tree: Archiving the (Monster) Tree
}

\author{
Somasree Sarkar \\ Assistant Professor, Department of English, Salesian College, Siliguri, West Bengal, India \& \\ Research Scholar, Department of English, University of North Bengal Siliguri, West Bengal, India \\ E-Mail: somasree.2008@gmail.com
}

\begin{abstract}
To view culture as a multispecies and not as an anthropocentric one is the call of the era. The liberal Humanist idea of human as an autonomous entity is to be debunked, as culture involves not only Homo sapiens, but also other species animals, plants, microbes, machines and hybrids. No species can dwell independently. Each species thrives in a network, interconnected and interdependent to each other. This network forms a culture of multispecies, where every being is akin to the other. Multispecies culture is all inclusive and all encompassing, disregarding the crippling binaries of human/ non-human, culture/nature, abled/disabled, normal/abnormal and so on. It is important to realize that each binary is an anthropocentric cultural construct. It must be discarded in order to create the culture of companion species, that is includes all forms of existence, not overlooking the 'unwanted' object as the minor 'other', in the anthropocentric view. The paper aims to argue that each species (highlighting the figure of tree in the paper) is an active actor in the bio cultural space. It strives to emancipate the figure of a tree from the clutch of anthropocentric notion, as 'nature'/ 'passive recipient'/ 'caregiver'/ 'mother'. To serve my purpose, I have chosen a Science Fiction, titled The Saliva Tree by Brian Aldiss. The fiction has an alien tree, functioning in a farm on the Earth. The tree has a horrendous physical appearance, is carnivorous and is nonsessile. All such features compile to render the arboreal creature as a 'monster', an identity imposed upon a misfit, considering it as a threat to the human-centered culture. I have argued how the farm with the 'monster' tree and other variety of species and machines becomes an archive, a dynamic biocultural space. It also enhances the botanical culture or 'FloraCulture', as termed by John Charles Ryan.
\end{abstract}

Keywords: Multispecies, Culture, Science Fiction, Monster, Tree/Plant, Body, Assemblage, Archive, FloraCulture

\section{INTRODUCTION}

"“The species' often means the human race, unless one is attuned to science fiction, where species abound" (18), says Donna Haraway in When Species Meet (2008). Science fiction is the ground for worlding of species and thus, existence of multiple species is possible. Haraway observes:

Looking back in this way takes us to seeing again, to respecere, to the act of respect. To hold in regard, to respond, to look back reciprocally, to notice, to pay attention, to have courteous regard for, to esteem: all of that is tied to polite greeting, to constituting the polis, where and when species meet. The knot companion and species together in encounter, in regard and respect, is to enter the world of becoming with, where who and what precisely what is at stake. (2008: 19)
The above quoted lines form the core of the culture of companion species. It is not only about the coexistence of multiple species, but is also about esteeming other species, as Haraway puts it, "Species interdependence is the name of the worlding game on earth, and that game must be one of response and respect. That is the play of companion species learning to pay attention" (2008:19). It is also about developing an interconnection or a network between multiple species and making of kin and kind. Donna Haraway talks about "making kin in the chthulucene", where 'chthulucene' is a multispecies epoch. Haraway explains, “"My' chthulucene [. . . .] entangles myriad temporalities and spatialities and myriad intra-active entities-in-assemblages - including the more-than-human, other-than-human, inhuman, and human-as-humus" (2016: 101). Haraway asserts that "all earthlings are kin in the deepest sense" (103) and defines kin as "assembling sort of word" (103). 'Making kin' suggests a culture that includes and recognizes pluralities (human, animals, plants, microbes, machines) and it encourages inter species relations. It creates ethnography of companion species.

To explore the interconnection between abounding species in a cultural space, I have chosen Brian Aldiss's novella, The Saliva Tree (1966). Aldiss is arguably the most influential figure in the field of British Science Fiction. In the introduction to an edition of Aldiss's well-known work, Hothouse, Neil Gaiman hails Aldiss's career as 'enormous' and further describes, "it has redefined British SF, always with a ferocious intelligence, always with poetry and oddness, always with passion; while his work outside the boundaries of science fiction, as a writer of mainstream fiction, gained respect and attention from the wider world" (2008). Aldiss's novella, The Saliva Tree surfaces the intrusion of an exobiological creature into the Earth's space. It appears as a tree-monster with its huge branches and with its salivation for earthly beings. The unconventional tree figure in the narrative exceeds the idea of propriety, imposed on trees/ plants by the anthropocentric culture. The Saliva Tree acknowledges the species, exterior to the topology of known. The exotic entrant into the society disrupts the usual habitat of the Norfolk farm. The disruption begins with the narrow escape of Gregory (the inquisitive observer in the farm) from drowning in the farm pond; it is then closely followed by the death of a dog at the farm. The production of the farm is mysteriously doubled and the farm gets overpopulated with litters. The treeintruder seems to have a developed nervous system, contrary to the popular belief of plants lacking in nervous 
system. It alters the taste of the produce of the farm to satiate its own taste and hunger. This suggests that it has sensory organs as well.

\section{THEORIZING ACTOR-NETWORK-THEORY IN THE CONTEXT OF THE SALIVA TREE}

The Saliva Tree radically tries to depict a society that is diluted to include an alien arboreal creature. The non-human intrudes the human society, becoming the prime actor, controlling the action. The space of Norfolk farm is the domain for the alien tree's exertion of power. There has often been a dichotomy between human and non-human in the Western thought. But, science fiction seeks to dissolve this division to feature a transformed society that assembles both human and non-human under its umbrella. The 'ActorNetwork-Theory' propounded by John Law is critical of the conventional dichotomies held by the Western philosophy:

Truth and falsehood, Large and small, Agency and structure, Human and non-human, Before and after, Knowledge and power, Context and content, Materiality and sociality, Activity and passivity... all of these divides have been rubbished in the work undertaken in the name of actor-network-theory. (1999: 03)

'Actor Network Theory' (ANT) as a sociotechnical approach considers both human and non-human elements as actors within a network. The same analytical framework, thus, is relevant for a human, an animal, a plant or a machine. Bruno Latour, in "On Actor Network Theory: A Few Clarifications" highlights:

An actor in ANT is a semiotic definition- an actant- that is something that acts or to which activity is granted by another... an actant can literally be anything provided it is granted to be the source of action. (1996: 373)

By recognizing both human and non-human actors, neglecting any unnecessary dichotomy between human and non-human, ANT acknowledges the heterogeneity of a society. It is concerned "to map the way in which they [actors] define or distribute roles, and mobilize or invent others to play these roles" (Law and Callon 1988: 285) and is not concerned with mapping interactions between individuals. The 'heterogeneous network' formed of 'heterogeneous associations' include all heterogeneous social materials: humans, non-humans, technologies, nature, politics, social orders. Every social material has a potential to exert power in the network. The entire society can, thus, be seen as a network of heterogeneous elements, inclusive of non-human (plants, animals, techno-ridden materials, texts). In The Saliva Tree, the farm is the social space where the network of heterogeneous actants is at play. The association built between the saliva tree and the other beings of the farm, is the effect of the unprecedented force exerted by the tree on the farm. The monster-tree's apparent power on the farm to adapt to the habitat in order to build the association is manifested through the excessive produce of the farm. In addition to this, the produce turns out to be inedible for human as the taste is altered to suit the appetite of the monster-tree, described as a "celestial visitant" and
"Aurigan" by Gregory Rolles. The tree has the ability to manipulate and scheme which proves that it possesses an active brain and intelligence. Gregory says to Nancy that they are being fed so that the tree in turn can feed on them:

It can only have been that at that time your systems were not full adjusted to the poison. Now they are. You're being fed up, Nancy, just like the livestock I'm sure of it! (The Saliva Tree 32)

\section{MONSTROSITY OF THE TREE}

The embodiment and behavior of the tree do not fit into the norms of being a plant/tree. Any such being with deviant embodiment and behavior is often identified as a 'monster' by dominant culture. The saliva tree represents the 'disabled other' that opposes the cultural notion related to plant behavior and form. In the anthropocentric view, the monster-tree with huge octopus-like trunks, having the ability to suck out terrestrial living beings, is a misfit in the plant community. So, the monster-tree may be considered a 'non-plant' owing to its unconventionality. 'Monster' is actually a cultural construction attached to particular physiognomies, shape and behavior. The idea of a 'monster' itself is eerie, breeding anxiety. The culture seeks to invent categories into which it can be suitably (re)located. As Jeffery Jerome Cohen delineates in "Monster Culture (Seven Theses)", "The monster's body quite literally incorporates fear, desire, anxiety, and fantasy, giving them life and uncanny independence. The monstrous body is pure culture. A construct and a projection ..." (04). The 'saliva tree' is categorized as 'Aurigan' from the outer space, a 'celestial visitant', or an alien. Such categorization also consciously excludes the 'monster' from the socio-cultural space. The word 'visitant' implies its temporary terrestrial location or its accidental intrusion into the society. 'Monster' exists with its exclusion from any conventional category. Cohen observes, "This refusal to participate in the classificatory "order of things" is true of monsters generally: they are disturbing hybrids whose externally incoherent bodies resist attempts to include them in any systematic structuration. And so monster is dangerous, a form suspended between forms that threatens to smash distinctions" (1996: 06). The sociotechnical criticism, 'Actor-Network-Theory', rubbishes off any ordered distinctions propagated by the Western culture by looking into the possible association between heterogeneous elements. It not only acknowledges the inter-heterogeneity among species but also acknowledges the intraheterogeneity within a species, thus ruling out the possibility of exclusion of any being that projects a deviant or a 'monstrous' behavior. It negates the rigid institutionalized species boundaries which is an important endeavor of Post human critical studies. The postmodern studies is directed towards the urge of recognizing multitude, as Cohen frames it in the following words, "We live in an age that has rightly given up on Unified Theory, an age when we realize that history (like "individuality", "subjectivity", "gender", and "culture") is composed of a 
multitude of fragments, rather than of smooth epistemological wholes" (1996: 03).

As a 'monster' smashes the distinctions of social categories and oversteps the cultural boundaries, both in terms of form and behavior, it is assumed to be 'grotesque', a somewhat disturbing and absurd figure. Grotesque also has a cultural context, as Geoffery Harpham notes, "the germ, the secret of the grotesque, lies not in the origins or derivations of the word, but in the conditions of a particular cultural climate, a particular artist, a particular audience. Perhaps we should approach the grotesque not as a fixed thing . . ." (1976: 461). The idea of 'grotesque' is variable. It exists in comparison, as we tend to compare the unfamiliar by placing it adjacent to the familiar. Anything that does not fit into the realm of the familiar assumes the garb of 'grotesque'. The description of the deadly monster-tree reveals its 'grotesque' form:

It was especially the size that frightened: this dread thing, remote from human form, was too big for earthly nature ten feet high, perhaps twelve! Invincible, and horribly quick ... (The Saliva Tree 35-36)

The further description of the arboreal being emphasizes more on its non-terrestrial nature that confers upon it the title 'monster':

It appeared, I suppose, most like some horrendous goose, but the neck must be imagined as almost as thick as the body indeed, it was almost all body, or all neck, whichever way you look at it. And on top of this neck was no head but terrible array of various sorts of arms, a nest of writhing cilia, antennae, and whips, for all the world as if an octopus were entangled with a Portuguese man-o'-war as big as itself, with a few shrimp and starfish legs thrown in. (The Saliva Tree 37)

The uncanny hybrid form of the non-earthly 'saliva tree' poses danger to a distinctive categorization and crosses cultural boundaries, hence a cultural misfit, or a 'monster'. The recognition of the 'monster' as a cultural misfit illuminates the cultural regime that seeks to outcast the unfamiliar or the unidentified. But, it is important to realize that 'monster' or 'grotesque' is nothing, but a cultural by product. It cannot be overlooked or discarded deliberately. Recognition of the 'other' in the dominant cultural space challenges the rigid cultural frame by pushing the cultural boundaries. The tree, both in shape and behavior, disrupts the conventional idea of a tree/plant. The 'saliva tree' not only defies the norms by projecting outrageous behavior, revealing horrible appearance, but also defies one common feature of a tree, that is immobility. The 'saliva tree' is mobile as it is described to possess extra ordinary quick pace. It is received as a shock, as an evil and an atrocious being. The tree with its monstrosity can be perceived as a disabled plant body, co-existing with the 'abled' or 'normal' plant bodies. The notions of 'abled', 'normal', 'disabled', 'deviant' are social constructs. Such classificatory regimes trigger biased thoughts, based on physical shape and abilities. This further reflects the prejudices and moral evaluations, reflected in cultural representations of deformed villains, diseased 'sinners'. These become the grounds for segregating them as 'others' from the dominant culture. The prejudice against the 'disable' or deviant species is a part of the exclusionary politics and 'speciesist' politics of anthropocentricism that posits human as the distinctive and the dominant life form. Anything outside the 'norm' is assumed to be essentially a threat to the society and a danger to human. Hence, there is a necessity to combat. In the novel, the tree is projected as a devil, "an invisible being of evil intent" (The Saliva Tree 10) from the other world, which has to be fought against, otherwise it can be the source of immense havoc. The 'disabled' plant body in contrast to the 'abled' plant bodies, is represented as a threat to the normative society. This assumption intensifies the anthropocentric vision of plant as a passive recipient. Here, an active botanical agent crosses the boundaries of human's conventional perception and hence, it is an outsider to culture.

\section{BODY AS AN ASSEMBLAGE}

The novella has traced physiological and anatomical fluidity through the saliva tree. The posthuman world, aided by technologies and scientific innovations, facilitates biological modulations, change and interchange into other bodies. The age of integral body, bounded body, one body and fixed body is over. The idea of 'whole' has given way to fragmentation, opposed to integration. Nothing is fixed, rather is in flux, whether it is physiological or ontological identity. Everything is fluid, capable of morphing into, or connecting with some other body (also with machines), assuming some other identity. Science fiction has contributed to the depiction of variant bodies, 'lesser' human bodies or culturally unrecognized bodies. The space of science fiction has grounded cyborgs that have colored human imagination to innovate crossed-bodies or transbodies. Pramod K. Nayar opines that human is perceived as "a constructed category built on exclusions even as its very identity is constituted through a close assemblage and interface with animals, machines and environments, in its most popular articulation often focuses on the body as a site for the new interpretations of the human" (Posthumanism 56). The new interpretation is not solely restricted to human, but also includes other beings. In the novella, the tree is seen to metamorphose into a metal body, an engulfing body. The tree in the imagination of Gregory is transfigured into the shape of a machine of a factory, emitting steam. It actually manifests the concern of the anthropocentric world which is rapidly being transformed into industrial from agrarian one, damaging the ecosystem. The tree assumes the hybrid body of a plant and a machine, a manifestation of the anxiety for the modern motor driven world. The anxiety is voiced through the words of Gregory:

People wanted to give themselves to the saliva tree. And although I didn't see this for myself, I had the distinct feeling that perhaps they weren't actually killed so much as changed into something else less human may be. And this time, I saw the tree was made of metal of some kind and was growing bigger and bigger by pumps you could 
see through the saliva to big armatures and pistons, and out of the branches steam was pouring. (The Saliva Tree 43)

The tree becomes the unknown force of destruction, taking metamorphosed shape of a machine which is seen as a force of subjugation, curbing the idyllic beauty of agrarian society. A tree which is conventionally perceived as 'nurturer' or 'giver', is projected as a 'taker', a fearsome intruder and a destroyer in the novel, opposed to the cultural perception. The monster-tree is a physical projection of the monstrosity of mechanical intruders into vegetation, damaging the tranquility. The anxiety and concern about the impending degradation by industrialization is once again expressed through the narrative:

He recalled the saliva tree; here as in the dream, it was as if agriculture had become industry, and the impulses of nature swallowed by the new god of Science. In the bark of the trees rose the dark steam of novel and unknown forces. (The Saliva Tree 45)

The 'saliva tree' takes the shape of a metamorphosed transbody, an assemblage of plant with machine. The technoaided modern society has enabled the emergence of body as an assemblage with biological composition of elements like machine or other digitalized components. The very notion of body as an assemblage with biological and nonbiological elements punctures the long held Enlightenment notion of body as 'coherent' or as an organic whole. The body as an interface is a site for intersection. In the novella, the plant body provides the site for intersection between organic and inorganic. One important point to be noted is that the 'saliva tree' is shaped into a machine puffing steam in the virtual space of Gregory's dream. It is the virtual space that allows the precarious body to flow into one another leading to incongruity. The plant-machine is materialized in the virtual space, but is also a manifestation of the reality of an increasing mechanization of the modern world. It stands as the metaphor for the transformation of agrarian society into an industrialized one. The figure of plant-machine acts in the liminal space between real and hyper real. The dream vision focuses on the condition of mixed reality and interfaced body. The body of transfigured plant also provides access to the virtual space, as Gregory lapses into his vision of the plant as a machine which he viewed in his dream. Once the plant body is shaped in his dream, it also becomes the medium of access to the virtual. Pramod K. Nayar observes, "The virtual is not simply a realm out there. Rather, the virtual envelops us just as the body becomes the means of access to that virtual. In this mixed-reality paradigm - in which all reality, virtual and physical, is mixed because the virtual is accessible only through the body- the materiality of the body is constitutive of the virtual even as the virtual is a means of developing our embodied subjectivity and experiential consciousness" (2014: 64-65). The divide between corporeal and virtual is, thus, dissolved and the body is mobilized and delocalized. The virtual is evoked in conjunction with the real when Gregory recalls the 'saliva tree' of his dreams on the occasion of hearing the uneasy noise of the mill and the engine. The sense of unease is compounded by the sounds of animals. The engine in the real space is assembled with the plant body in the virtual space. The plasticity of the plant body creates a smooth space allowing the overflow of real and virtual, concrete and abstract. The body is a fluid or a plastic entity, and it is always 'becoming' while operating in the smooth space. It can be assessed as an 'event' (in Deleuzian sense) that is a constituent of the smooth space. Deleuze claims, "Everything is event", in his lecture on 10 March, 1987. James Williams while reflecting on the lecture by Deleuze observes that for Deleuze, "when everything is event, everything is essentially becoming" (2011: 80). 'Event' for Deleuze is a never ending process without any limit, any origin or end. It is rhizomatic in nature, connecting to every other. The plant body performatively continues to evolve and emerge by transgressing and transcending the physical boundaries.

\section{ARCHIVE AS A DYNAMIC CULTURAL SPACE}

The connection and interconnection between the living species and also with its surroundings creates a dynamic cultural space, accommodating diverse living communities. The Norfolk farm is an archive conserving, producing and showcasing the variety of species (terrestrial and nonterrestrial both). The bio-diversity within the farm enables access to accumulation of records of various species which may be of historical interest, to be referred to for further research. The farm archiving variety of plant species is pivotal to building up of rich 'botanical heritage'. The restricted space of the farm is suitably conditioned for unrestricted fruition and growth of over enlarged fruits. The plants bearing pear-shaped strawberries and football-shaped apples appear distorted to culture, nonetheless the distorted form itself is indigenous to the farm and hence, worth conserving and archiving for developing a distinct 'botanical heritage'. Ryan says, "In theory and practice, the interdisciplinarity of botanical heritage - as both biological and cultural, that is, as biocultural - is an asset in terms of archival scope, inclusiveness, and prospective relevance to different users of present and future" (2015: 62). Jacques Derrida in his "Archive Fever" (1995) theorizes the concept of archive. He says the term 'archive' refers "to the arkhe in the physical, historical, or ontological sense, which is to say to the originary, the first, the principal, the primitive, in short to the commencement. But even more, and even earlier, "archive" refers to the arkhe in the nomological sense, to the arkhe of commandment" (09). Derrida also refers to Greek arkheion as the source of meaning of "archive". Arkheion means "a house, a domicile, an address, and the residence of superior magistrates, the archons, those who commanded" (09). "Archive' thus, refers to the house or place where "official documents are filed" (10) and archons are "documents' guardian" (10), in the words of Derrida. "It is thus, in this domiciliation, in this house arrest, that archives take place", opines Derrida (1995: 10). Derrida in the treatise borrows largely from Freud's Beyond the Pleasure Principle (1961) to theorize the concept of 'archive'. According to Derrida, the economy of archive is composed of the force what he calls the "death 
drive", "aggression drive" or "destruction (Destruktion) drive" (Derrida and Prenowitz 13) and all the three drives are "mute" or "stumm" (Derrida and Prenowitz 1995: 13). $\mathrm{He}$ also terms the death drive or destruction drive as "anarchivic" and "archioviolithic" (Derrida and Prenowitz 1995:14). This death drive is associated with Thanatos. An oppositional force is also at play which is the drive to archive and conserve, associated with pleasure principle, Eros. Derrida gives his Freudian interpretation of archive:

Another economy is thus at work, the transaction between this death drive and the pleasure principle, between Thanatos and Eros, but also between the death drive and this seeming dual opposition of principles, of arkhai, for example the reality principle and the pleasure principle. (1995: 14)

Archive thus, resists the death drive to the condition of effacing. The archive "salvages the seeds of the past for the fruition of the future despite the archioviolithic floodwaters of physical decay, technological obsolescence, cultural obscurity, social disregard, and economic penury", in opinion of Ryan (2015: 64).

\section{NORFOLK FARM AS AN ARCHIVE}

In the novel, the archive of East Anglia farm at Norfolk is driven by the oppositional forces of death drive and archival drive. The death drive is represented by Gregory who forces to destroy the archive as he realizes the destructive nature of the alien plant, preserved in the archive. He is the cultural capitalist who seeks to value the cultural capitalism of viewing plants as tame and passive beings and any deviation is perceived by him as a distortion and as a danger. He is the one who forcibly tries to impose order on the farm as he considers it to be disordered and perverted primarily by the intrusion of the tree. Gregory wills to reestablish the lost balance, even at the expense of destruction of the archive, represented by the farm. Gregory idealizes the farm by comparing it to the Eden where everything is harmonized and it is an idyllic state. But however, the idyll of the farm is disrupted and he fends for its revival. In his letter to H.G Wells, he expresses his gloom over the loss the Edenic state of the farm.

So you see how the farm is now a place of the damned! Once, I thought it might even become a new Eden, growing the food of the gods for men like gods. Instead alas! The first meeting between humanity and beings from another world has proved disastrous, and the Eden is become a battleground for a war of worlds. (The Saliva Tree 38)

The oppositional force is materialized through Joseph Grendon, the owner of the farm. He is the one who holds a passionate affection towards his farm-archive. After repeated warnings by Gregory, he is unable to change his mind of leaving the farm. He is the one who preserves and archives. He derives pleasure (Eros) from production and conservation of plants and does not bother about the danger that can be posed by the alien plant. For Grendon the tree is not an alien once it has encroached upon the boundaries of the farm. He accepts the tree as one of them. He also appreciates the aid that the 'Aurigan' has provided for accelerating the growth in plants and animals in his farm. Grendon says to Gregory, "So much better for us!" (The Saliva Tree 32), when Gregory warns Grendon about the extraordinary growth in the produce of the farm. He is the violent drive that protects the archive from destruction. Grendon resists the destructive force exerted upon by Gregory and tries to keep him away:

"Now you be warned, Gregory," the farmer repeated.

"You be off my land by noon by the sun, and that mare of yours, or I won't answer for it." He marched out into the pale sunshine, and Neckland followed. (The Saliva Tree 32)

The archive is determined by the two polarized drives and the liminal space is created at the threshold of the two forces. Archive is drawn from the memory, consigned to the past, holding historical importance, and calls into "question the coming of the future" (Derrida and Prenowitz 1995: 26). Archive in a liminal space delimits the paradigm and hence has the internal contradiction. The archive drive of Grendon advocates the archiving of the unusual species and also of the over grown fruits and extraordinary increased animal produce in the farm. Stuart Hall in Constituting an Archive (2001) discusses about the idea of "living archive". "“Living' means present, on-going, continuing, unfinished, open-ended" (Hall 2001: 89). Archive is not a static space, but is rather an active one where influx of information and documentation continues. It is a counter for negotiation between the past and the present, also building the future. Archive is the "discursive formation" (Hall 2001: 90) of heterogeneous texts including historiographies, stories, anecdotes, written documents, visual and audio-visual documents, digital texts. It is multidisciplinary in nature and is 'discursive'. It cannot be material, rather is cultural. In The Saliva Tree, the Norfolk farm is this 'living archive' which is the junction for human and non-human actors and also for biological and non-biological bodies. It is a dynamic bio cultural space that allows the assemblage of human and non-human, organic and non-organic. Such heterogeneity makes the farm a 'living archive'.

Ryan observes, "The living archive becomes a place of creative production - in the present tense - where forthcoming material is inspired and created from "inert collections" ..." (2015: 66). Grendon, being the creative archivist, recognizes the worth of 'Flora Culture' (as Ryan coins) or the plant-based culture that caters to the intensification of his sense of possession for his archive, evident from his use of the term "my land". Ryan suggests that "the heterogeneity of the archive mirrors the heterogeneity of the plants themselves (i.e. biodiversity) and the different conditions to which they are subjected (both natural and anthropogenic)" (2015: 67). The Norfolk farm is not just the "prison house of the past" (Hall 2001: 89), but is also the living present. The 'Flora Culture' or botanical culture endeavors to accommodate diverse collections of plant species as no single plant type can form a rich botanical culture. 'Flora Culture' is further enriched by the 
diverse texts that surround each plant, making each one exclusive and distinct from the other. Archive stimulating 'Flora Culture' preserves the multiple texts that tell the story of the botanical world. Moreover, 'Flora Culture' or botanical culture does not pertain only to plants, but it includes the interplay of relationships between plants, animals, humans and also non-living mechanical and digital devices in all their complexities. Here again, we can invoke Donna Haraway's notion of 'companion species' which tells that no species exists in isolation, rather stays in close relation with all other diverse species, including both living beings and non-living machines. In today's techno-aided world, culture cannot be assessed excluding the digitized and mechanized arena. It is important in the perception of any being in the multicultural and multispecies space. Multispecies society also dismantles the anthropocentric view of seeing human as the center, in isolation from the rest. Infact, no species can exclusively be a part of the culture. It has to inclusively be a part of the culture with all its intricacies and conflicts. In The Saliva Tree, the farm is the multispecies space that includes human, animals, plants, non-earthly beings and machines. It is an excellent example of a space that promotes biodiversity and where each being exists as a 'companion'. The word, 'companion' refers to the idea of kinship and cooperation, indicating that every species in the farm must be a kin to each other. The term 'companion species', moreover, does not prioritize any particular being's existence, instead advocates the cohabitation of each species, despite the plurality. The space of the farm also tries to fit in steam engine and other machines. Often in the text, readers are given the impression of the co-existence of machines, human and animals through the conveyance of sounds of machine on one hand and sounds of animals on the other. There is a confluence of "the old mill shriek", the pumping sound of "steam engine" (The Saliva Tree 46) and the raging sounds of dogs in the farm. There is a co-presence of terrestrial man-made machines and of machine from outer realm within the space of the farm. The farm in a way occupies an extra-terrestrial space where terrestrial and non-terrestrial entities (both living and non-living) cohabit. This again reiterates the idea of 'living archive' where there is a continuous never-ending negotiation between the archived species. The diversity makes it archivable.

\section{CONCLUSION}

The heterogeneity opposed to homogeneity; plurality opposed to singularity; do not mean a macabre condition or a condition of disharmony. But, the multiplicity has been presented as an uneasy mixture, in the narrative. The lack of harmony is repeatedly addressed by Gregory and he is the force that seeks to establish harmony and coherence. He represents the farm as a damned place where a creature of 'evil intent' resides. He takes it up as a moral responsibility to purge the field of the 'evil'. Gregory is a representative of the Western anthropocentric society, upholding the politics of 'othering' anything outside the Eurocentric norm of thought, intrinsic to the Western Enlightenment view. Gregory tries to convince Grendon to evacuate the farm, to fight the 'other' creature from other planet and to recognize it as harmful and menacing. Gregory does every possible act to identify the creature and to confront it, so that he can remain true to his moral responsibility of saving the farm from any foreign encroacher, re-establishing the dominant human culture. Grendon emerges as a figure of resistance to the anthropocentric view. He resists Gregory's conviction of fighting the 'monster'. The word 'monster' itself is a creation of the anthropocentric culture, a means to marginalize the deviant. The 'monster-tree' is attempted to be pushed forth to the dominant cultural platform, but at the end of the novella, the tree with its machine exits the biocultural space of the farm. So, the novella valorizes the anthropocentric vision of harmony through exclusion of the intruder, the 'other'. Falling into the anthropocentric trope, the novel does not encourage any deviation from the norm. Sending off the 'saliva tree' from the terrestrial field perhaps indicates the power of decision making wielded by human of not accepting a creature, outside the horizon of human knowledge. The novel after offering a wide paradigm for critical interpretation of a multispecies culture seems to succumb to the norms of anthropocentricism.

\section{REFERENCES}

[1] Aldiss, Brian. The Saliva Tree, Retrieved from http://dlx.book.org/my genesis/20/c2a904b58c90cf85e03877a4a7c2794/

[2] Cohen, Jeremy Jerome. (1996). "Monster Culture (Seven Theses)." Monster Theory: Reading Culture. Minneapolis: University of Minnesota Press, 3-25.

[3] Derrida, Jacques, and Eric Prenowitz. (1995). Archive Fever: A Freudian Impression. JSTOR, Diacritic, 25(2), 9-63. Web. 14 Feb 2018.

[4] Gaiman, Neil. (2008). Introduction. Hothouse. By Brian Aldiss. U K Modern Penguin Classics.

[5] Hall, Stuart. (2001). Constituting an Archive. Third Text, 15(54), 8992. Web. Retrieved from https://doi.org/10.1080/095288201085 76903

[6] Haraway, Donna. (2016). Staying With the Trouble: Making Kin in the Chthulucene. Durham: Duke University Press.

[7] Haraway, Donna. (2008). When Species Meet. Minneapolis: University of Minnesota Press.

[8] Harpham, Geoffrey. (1976). The Grotesque: First Principles. JSTOR. The Journal of Aesthetics and Art Criticism, 34(4), 461-468. Web. 7 March 2019.

[9] Latour, Bruno. (1996). On Actor-Network Theory: A Few Clarifications. Soziale Welt, 369-381. JSTOR. Web. 8 March 2019.

[10] Law, John. (1999). After ANT: Complexity, Naming and Topology. Actor Network Theory and After. Ed. J. Hassard and John Law. Oxford: Blackwell Publishers.

[11] Law, John, \& Michel Callon. (1988). Engineering and Sociology in a Military Aircraft Project: A Network Analysis of Technological Change. Social Problems, 35(3), 284-297. JSTOR. Web. 8 March 2019.

[12] Nayar, Pramod. K. (2014). Posthumanism. Cambridge: Polity Press.

[13] Ryan, John Charles. (2015). Posthuman Plants: Rethinking the Vegetal Through Culture, Art, and Poetry. Champaign: Common Ground Publishing LLC.

[14] William, James. (2011). Event. Gilles Deleuze: Key Concepts. Ed. Charles. J. Stivale. New York: Routledge, 80-90. 